\title{
How to Make the Right Diagnosis in Neutropenia
}

\author{
Elena E. Solomou*, Christina Salamaliki, Maria Lagadinou \\ Department of Internal Medicine, University of Patras Medical School, Rion 26500, Greece
}

\section{ARTICLE INFO}

\section{Article History}

Received 11 November 2020

Accepted 11 February 2021

\section{Keywords}

Neutropenia

infections

drugs

differential diagnosis

\begin{abstract}
Isolated neutropenia without anemia or thrombocytopenia is a common clinical problem. The etiology of neutropenia may vary from transient bone marrow suppression, caused by self-limited viral illnesses, to previously undiagnosed congenital syndromes or serious systemic diseases. Consequently, determining the underlying cause of neutropenia and what treatment is required can be challenging. Acquired neutropenia is common and most of the times an etiologic factor can be found. Congenital neutropenia $(\mathrm{CN})$ is rare, and we still have a lot to learn from mutational analysis as to the exact role of gene abnormalities in the pathogenesis of these complex diseases. This mini-review discusses a proposed approach to neutropenia in the adult patient.
\end{abstract}

(C) 2021 International Academy for Clinical Hematology. Publishing services by Atlantis Press International B.V. This is an open access article distributed under the CC BY-NC 4.0 license (http://creativecommons.org/licenses/by-nc/4.0/).

\section{INTRODUCTION}

Isolated neutropenia without anemia or thrombocytopenia is a common clinical problem [1]. Neutropenia is the reduction in the absolute number of circulating neutrophils (ANC), taking into account that normal neutrophil counts may vary according to age and ethnicity [2].

The etiology of neutropenia may vary from transient bone marrow suppression, caused by self-limited viral illnesses, to previously undiagnosed congenital syndromes or serious systemic diseases [3]. Consequently, determining the underlying cause of neutropenia and what treatment is required can be challenging. This mini-review discusses a proposed approach to neutropenia in the adult patient.

\section{NEUTROPENIA: DEFINITION}

Leukopenia comes from the greek words " $\lambda \varepsilon v \kappa o ́ c$ " meaning white and " $\pi \varepsilon v i \alpha$ " meaning deficiency. Usually, the term leukopenia is used interchangeably with the term neutropenia because the neutrophil counts are the most important for the prevention of infections [4]. Evaluation of a patient with neutropenia should take into account how acutely neutropenia developed, the duration and clinical symptoms associated with it and, finally, the age and general condition of the patient [1-4].

Neutrophil production is controlled by various factors, mainly granulocyte colony-stimulating factor (G-CSF), granulocyte/ macrophage CSF and IL-3. The rate of neutrophil production depends on the rate of apoptosis; their clearance by macrophages stimulates IL-23 production. IL-23 results in IL-17A production, which eventually leads to G-CSF secretion [4].

"Corresponding author. Email: esolomou@upatras.gr; elenasolomou@hotmail.com Peer review under responsibility of the International Academy for Clinical Hematology
Neutropenia can be mild (when the ANC is $1000-1500 / \mu \mathrm{L}$ ), moderate (ANC 500-1000/ $\mu \mathrm{L})$, or severe $(\mathrm{ANC}<500 / \mu \mathrm{L})[5]$. We classify neutropenia as very severe when the ANC is less than $200 / \mu \mathrm{L}$. Categorizing neutropenia severity based on the ANC is useful in order to determine those patients with increased risk of possible life-threatening infections (Table 1). In children up to 12 months of age the lower limit of the normal ANC is 1000/ $\mu \mathrm{L}$; In older children and in adults, it is $1500 / \mu \mathrm{L}$. Individuals from some ethnic groups (mainly African and some Middle-East populations) may have lower neutrophil counts [6]. Patients with severe or very severe febrile neutropenia should be admitted to the hospital, irrespectively of the potential causes, and broad-spectrum antibiotics should be administered before a definite cause of the neutropenia is determined [7].

Neutropenia can be acute or chronic [2]. When neutrophil consumption is quick, and their production is impaired, acute neutropenia may present even after a few days. If it lasts more than 3 months and is confirmed on at least three samples taken over several weeks we define neutropenia as chronic. Chronic neutropenia results from reduced neutrophil production, increased destruction, or excessive splenic sequestration.

\section{WHAT CAUSES NEUTROPENIA?}

In the majority of cases, neutropenia is secondary to causes extrinsic to bone marrow myeloid cells; less frequently it can be an acquired disorder of myeloid progenitor cells and, rarely, it is an intrinsic defect of the proliferation and maturation of myeloid progenitor cells $[8,9]$.

Congenital neutropenia $(\mathrm{CN})$ can be classified as ethnic, benign familial, cyclic and severe congenital neutropenia [10]. Usually, benign familial neutropenia and ethnic neutropenia are mild, without a history of recurrent infections [11]. Neutropenia can be encountered in some Mediterranean and African populations; a 
Table 1 Most common sites of infection and pathogens isolated in neutropenic patients

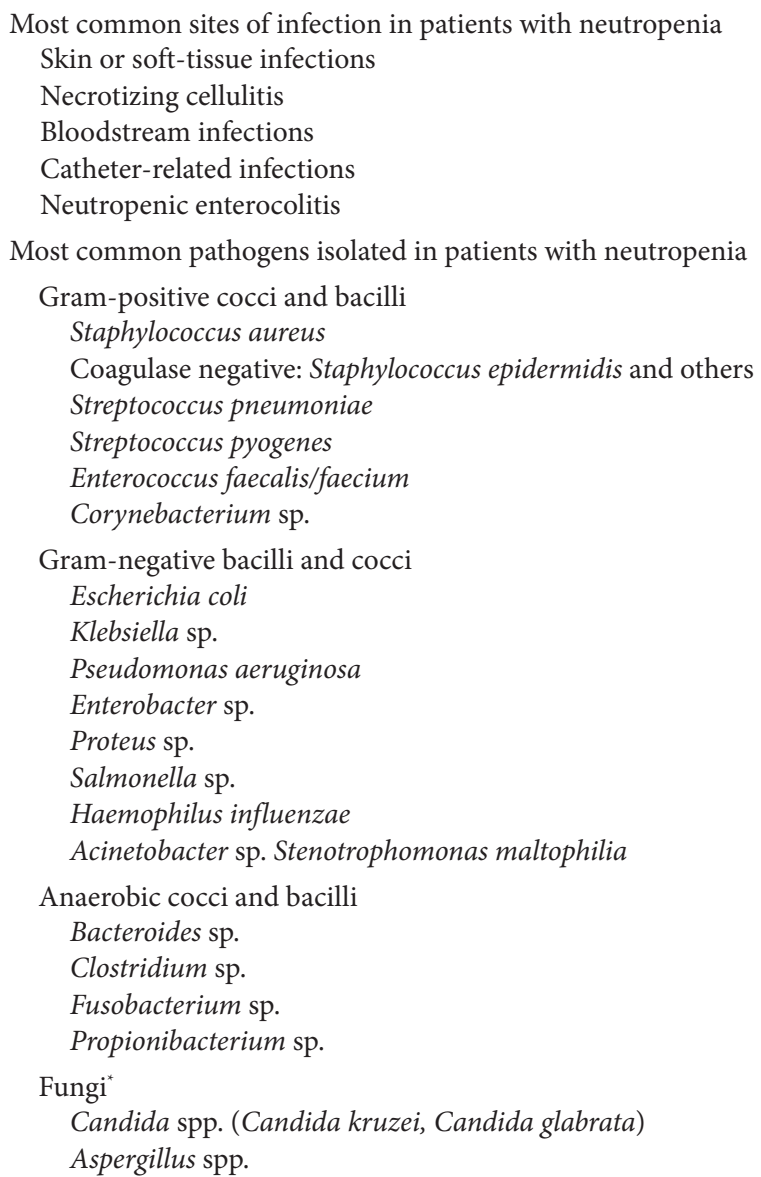

"As the duration of neutropenia increases, the risk for invasive fungal infections increase, and include: Invasive Candidiasis, Invasive Aspergillosis (Pulmonary aspergillosis), Mucormycosis, trichosporonosis, fusariosis and cryptococcosis (less common).

polymorphism in the Duffy antigen receptor complex (DARC) gene has been identified, but the mechanistic association of neutropenia with this polymorphism is unknown. Familial benign neutropenia is phenotypically similar to ethnic neutropenia. It is usually hereditary, but sporadic cases have also been described. No gene involvement has been detected up to date.

Severe congenital neutropenia (SCN) is characterized by agranulocytosis and recurrent, severe infections that begin during infancy [12]. Mutations in several neutrophil-specific genes (more common ELANE and HAX1) have been described. SCN carries a $10-30 \%$ lifetime risk of developing acute myelogenous leukemia [13]. Prognosis has been improved by the routine administration of G-CSF.

Cyclic neutropenia is a rare congenital disease characterized by episodes of self-limited neutropenia that recur every 2-5 weeks [14]. The syndrome is usually of mild severity, although some patients can develop infections or oral ulcers during their neutrophil nadir. Cyclic neutropenia is an autosomal dominant syndrome which, like SCN, has been shown to result from mutations in the ELANE gene; such mutations are encountered in almost $100 \%$ of the patients. Unlike SCN, there is no increased risk of developing acute myelogenous leukemia (AML). An interesting observation is that the same mutation has been described in family members and some of them develop SCN and others cyclic neutropenia. It is not understood how a single mutation can lead to different phenotypes. $\mathrm{CN}$ is usually associated with a mild phenotype and can often be diagnosed in adults. If $\mathrm{CN}$ is suspected, twice weekly blood counts for 4-6 weeks may establish the cyclic pattern observed in this disease. Usually, we need to reassure the patients that they are not at risk of developing acute leukemia. Neutropenia can also be found as part of the spectrum of other congenital syndromes like Shwachman-Diamond Syndrome, Fanconi anemia, or Dyskeratosis Congenita $[1,10]$.

Acquired neutropenia is significantly more common than the congenital form. Various infections, drugs and autoimmune diseases have been implicated in the etiology of acquired neutropenia [1,3]. Although all infections can potentially be associated with neutropenia, it is viral infections which most commonly decrease neutrophil counts. Epstein-Barr virus (EBV), human immunodeficiency virus (HIV), hepatitis viruses, Variccela-zoster virus, rubella, measles, influenza, Brucella, rickettsial, and mycobacterium infections, all can be accompanied by neutropenia (Table 2) [15-22]. In most infections, the neutropenia is usually brief and self-limited, but in EBV and HIV infections neutropenia can be prolonged [21,22]. Severe sepsis can result in neutropenia, usually because of exhaustion of the granulocyte reserves; this has been associated with a poor prognosis [23].

Drugs represent one of the most common causes of neutropenia $[24,25]$. There is a long list of drugs that can be associated with neutropenia; the most common are non-steroidal anti-inflammatory drugs, antibiotics (semisynthetic penicillins, and cephalosporins), ticlopidine, carbimazole, antipsychotics, diuretics, and anti-epileptic drugs. Rituximab is a drug that is widely used in many hematological and autoimmune diseases; it can be associated with neutropenia during treatment or with a late-onset neutropenia [26,27]. Drug-induced neutropenia can range from mild to idiosyncratic agranulocytosis. Patients who develop early neutropenia/agranulocytosis while taking drugs known to be associated with this problem should discontinue the drug, though, if the neutropenia is mild, drug maintenance can be considered under close monitoring of the ANC [28].

Table 2 Infectious causes of neutropenia. Viral and parasitic infections can cause mild, moderate or severe neutropenia

\begin{tabular}{|c|c|c|c|}
\hline $\begin{array}{l}\text { Type of } \\
\text { infection }\end{array}$ & & $\begin{array}{c}\text { Severe } \\
\text { neutropenia } \\
(<500 / \mathrm{L})\end{array}$ & $\begin{array}{c}\text { Mild }(1000-1500 / \mathrm{L}) \text { to } \\
\text { moderate }(500-1000 / \mathrm{L}) \\
\text { neutropenia }\end{array}$ \\
\hline \multirow[t]{12}{*}{ Viral } & Epstein-Barr & & $*$ \\
\hline & Cytomegalovirus & & * \\
\hline & HIV & $*$ & * \\
\hline & Hepatitis & & $*$ \\
\hline & Influenza & & $*$ \\
\hline & Parvovirus B19 & & $*$ \\
\hline & Sars-CoV2 & & $*$ \\
\hline & Typhoid & & * \\
\hline & Tuberculosis & * & * \\
\hline & Rickettsial & & * \\
\hline & Tularemia & & $*$ \\
\hline & Paratyphoid & * & $*$ \\
\hline \multirow[t]{2}{*}{ Parasitic } & $\begin{array}{l}\text { Plasmodium } \\
\text { vivax }\end{array}$ & * & \\
\hline & $\begin{array}{l}\text { Plasmodium } \\
\text { falciparum }\end{array}$ & * & \\
\hline
\end{tabular}


Most of the common dietary deficiencies that cause cytopenias are usually associated with pancytopenia rather than isolated neutropenia $[29,30]$. Folate, vitamin B12, and copper deficiency often are accompanied with neutropenia of variable severity. Deficiency of the former two is usually characterized by megaloblastic anemia and thrombocytopenia [31]. Copper deficiency should be considered in patients who have any history of malabsorption or gastric surgery [32]. Anorexia nervosa is usually associated with mild neutropenia [33].

Autoimmune neutropenia can be primary or secondary, and is more often mild to moderate in severity [34]. Primary autoimmune neutropenia develops during the first year of life and usually resolves by the second year. No special treatment is required; usually antibiotics for infections and G-CSF to increase ANC counts are used until resolution. Secondary autoimmune neutropenia is associated with other autoimmune diseases (i.e. systemic lupus erythematosus or rheumatoid arthritis) [35]. Flares of the underlying disease can trigger neutropenia; however, this neutropenia usually responds to steroids or intravenous gamma globulin. In Felty syndrome, splenomegaly is found and neutropenia can be severe; at present, Felty syndrome is rarely seen because of early treatment of rheumatoid arthritis [36].

In any patient with unexplained neutropenia we need to exclude bone marrow dysplasia, or marrow infiltration by neoplasms such as leukemia, lymphoma or myeloma [37]. Chronic idiopathic neutropenia is a diagnosis of exclusion if all other sought causes have been ruled out [38]. The pathogenesis of the disease is so far unknown, but it shares abnormalities with aplastic anemia; the presence of activated $\mathrm{T}$ cells in the circulation and oligoclonal $\mathrm{T}$ cells, increased TNF- $\alpha$ and TGF- $\beta$, increased apoptosis in the bone marrow, increased levels of FLT3 ligand, and increased TLR4 in monocytes leading to increased levels of inflammatory cytokines are some of the abnormalities described and characterize the disease. It is common in the Greek island of Crete, but the ANC are rarely less than $800 / \mu \mathrm{L}$. The bone marrow smears and cytogenetics are normal, and only sometimes hypoplasia in the myeloid precursors can be seen [39].

\section{HOW WE APPROACH A PATIENT WITH NEUTROPENIA?}

Management of an adult patient presenting with neutropenia will be dictated by his/her general condition. If the patient is febrile, acutely ill and his/her vital signs show signs of sepsis, he/she should be immediately admitted to the hospital and broad spectrum antibiotics should be initiated [40]. The initial management will not require knowledge of the exact cause of the neutropenia if the condition is critical. Following stabilization of the patient, an algorithm, potentially leading to the diagnosis, is followed (Figure 1). A detailed medical history will reveal usage of drugs and, when available, previous complete blood counts will determine for how long the patient has been neutropenic. History of infections, or any previous hospitalizations due to infections, as well as the site of infection (e.g., otitis, sinusitis, soft tissue infections) will help with the diagnosis. Any history of malnutrition or malabsorption, and history of gastric surgery should be considered.

Perhaps the most important cause of neutropenia is drugs [41]. Medications are believed to account for $70 \%$ of all cases of neutropenia. One should consider recent initiation of any medication, including over-the-counter anti-inflammatory and herbal formulations. Discontinuation of all drugs suspected to be responsible for the observed neutropenia should be one of the first steps in patient management. Drug-induced agranulocytosis may be fatal with mortality rates as high as $12-25 \%$. Usually, experts suggest that neutropenia in an adult should be considered drug-induced until proven otherwise [8]. If there is no drug or recent infection exposure, other causes of neutropenia as previously described are considered. Dietary causes and autoimmune diseases, which usually present with cytopenias in more than one lineage, should be considered in the initial evaluation. Weight loss, fever or night sweats should prompt an evaluation to exclude an underlying malignancy where neutropenia can be prominent. A gradual decline in neutrophils can be associated with infection, autoimmune disease, malignancies, or drugs. If splenomegaly is present, exclusion of cirrhosis, sarcoidosis, and glycogen storage diseases among others, is indicated.

The initial screening must include a complete blood count and biochemical profile, including renal and liver function tests, along with a peripheral blood smear examination. For patients with minimal or no symptoms of infection or other illnesses, serial blood counts twice a week for 4-6 weeks are recommended. If a cyclic pattern is present, the diagnosis of cyclic neutropenia is established. All patients should be tested for HIV and hepatitis viruses, along with a basic autoimmune profile (anti-nuclear antibodies and rheumatoid factor) C-reactive protein (CRP) and erythrocyte sedimentation rate (ESR). Even in the absence of lymphocytosis, peripheral blood flow cytometry analysis can be helpful in some instances to exclude large granular lymphocytosis/leukemia [42]. Bone marrow aspiration and core biopsy are considered mandatory if neutropenia does not resolve after discontinuation of drugs to (exclude myelodysplastic syndromes, leukemia, or other malignancy), or if any other cause of neutropenia is not prominent. A sample from bone marrow aspirate should be used for karyotype and flow-cytometry analysis. Infectious causes such as mycobacterium and fungi can also be evaluated if present in the bone marrow biopsy.

The clinical significance of anti-neutrophil antibodies is not clear and, even if the result is positive, their role cannot be predicted [43]. Five different types of neutrophil antigens can be examined human neutrophil antigen (HNA1-5). Their presence in chronic idiopathic neutropenia and in neutropenia associated with other autoimmune diseases is common. On the other hand, false positive results are frequent, due to increased Fc receptors on neutrophils, increased tendency of neutrophils to spontaneous fluoresce, and increased tendency of neutrophils to aggregate in vitro. They can also be found in healthy subjects with no history of autoimmune disease or neutropenia. It is noteworthy to mention that there is no correlation between anti-neutrophil antibodies and response to treatment with immunosuppressive agents.

\section{HOW TO TREAT THE NEUTROPENIC PATIENT?}

In most cases, no specific treatment is needed for patients with neutropenia [44]. The first step in the management is discontinuation of all drugs that can be associated with neutropenia. Usually, treatment of the underlying disorder results in increased ANC, and 


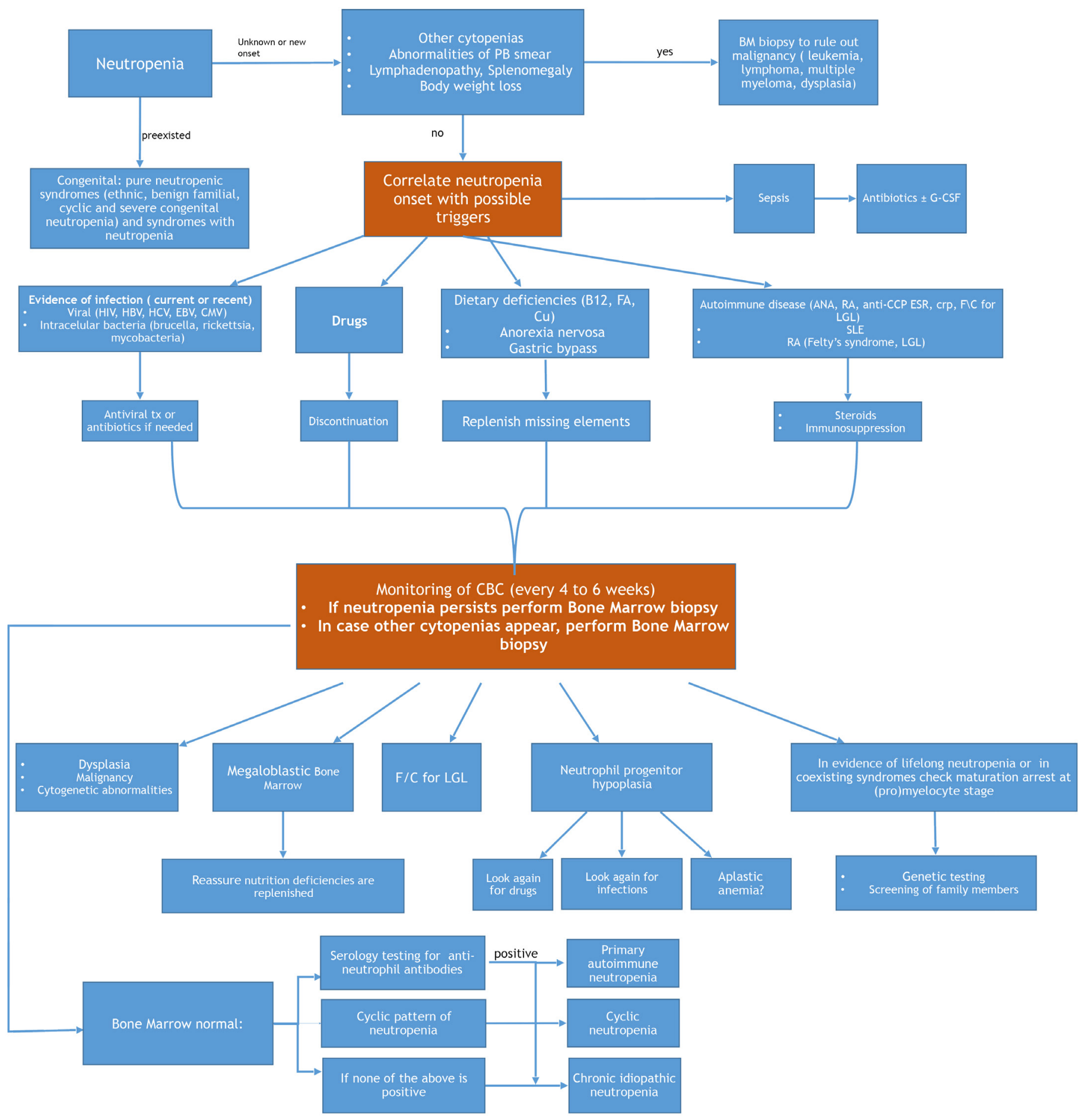

Figure 1 How to approach and diagnose neutropenia in an adult patient. PB, peripheral blood; BM, bone marrow; CMV, cytomegalovirus; tx, treatment; B12, vitamin B12; FA, folic acid; Cu, Copper; ANA, anti-nuclear antibody; RF, rheumatoid factor; anti-CCP, anti-cyclic citrullinated peptides; LGL, large granular lymphocytic leukemia; SLE, systemic lupus erythematosus; RA, rheumatoid arthritis; CBC, complete blood count; f/c, flow cytometric analysis.

the neutropenia resolves. In autoimmune neutropenia, low dose of cyclophosphamide or methotrexate has been shown to be useful. If the patient is febrile with septic symptoms, admission to the hospital is required, regardless of the cause of neutropenia. Broad spectrum antibiotics are administered to cover for all possible pathogens (Table 1).
The use of G-CSF is reserved for patients with severe infections [45]. If recurrent skin, soft tissue infections or ulcers occur, G-CSF can also be given. In any case, the minimum necessary doses of G-CSF are administered in order to maintain an ANC count between 250 and $300 / \mu \mathrm{L}$. The use of G-CSF is not associated with leukemic transformation in chronic neutropenia. 


\section{CONCLUSION}

In summary, acquired neutropenia is common and most of the times an etiologic factor can be found. Congenital neutropenia is rare, and we still have a lot to learn from mutational analysis as to the exact role of gene abnormalities in the pathogenesis of these complex diseases.

\section{CONFLICTS OF INTEREST}

The authors declare they have no conflicts of interest.

\section{AUTHORS' CONTRIBUTION}

All authors wrote and edited the manuscript.

\section{REFERENCES}

[1] Boxer LA. How to approach neutropenia. Hematology Am Soc Hematol Educ Program 2012;2012;174-82.

[2] Munshi HG, Montgomery RB. Severe neutropenia: a diagnostic approach. West J Med 2000;172;248-52.

[3] Gibson C, Berliner N. How we evaluate and treat neutropenia in adults. Blood 2014;124;1251-8; quiz 1378.

[4] Borregaard N, Boxer LA. Disorders of neutrophil function. In: Kauskhansky K, Lichtman MA, Beutler E, Kipps TJ, Seligshon U, Prchal JT, editors. Williams hematology, 8th Ed. New York, NY: McGraw-Hill; 2010, pp. 951-86.

[5] Papadaki HA, Pontikoglou C. Pathophysiologic mechanisms, clinical features and treatment of idiopathic neutropenia. Expert Rev Hematol 2008;1;217-29.

[6] Reich D, Nalls MA, Kao WHL, Akylbekova EL, Tandon A, Patterson N, et al. Reduced neutrophil count in people of African descent is due to a regulatory variant in the Duffy antigen receptor for chemokines gene. PLoS Genet 2009;5;e1000360.

[7] Averbuch D, Orasch C, Cordonnier C, Livermore DM, Mikulska M, Viscoli C, et al. European guidelines for empirical antibacterial therapy for febrile neutropenic patients in the era of growing resistance: summary of the 2011 4th European Conference on Infections in Leukemia. Haematologica 2013;98;1826-35.

[8] Palmblad J, Dufour C, Papadaki HA. How we diagnose neutropenia in the adult and elderly patient. Haematologica 2014;99;1130-3.

[9] Frater JL. How I investigate neutropenia. Int J Lab Hematol 2020;42;121-32.

[10] Fioredda F, Calvillo M, Bonanomi S, Coliva T, Tucci F, Farruggia P, et al. Congenital and acquired neutropenias consensus guidelines on therapy and follow-up in childhood from the Neutropenia Committee of the Marrow Failure Syndrome Group of the AIEOP (Associazione Italiana Emato-Oncologia Pediatrica). Am J Hematol 2012;87;238-43.

[11] Jacobs P. Letter: Familial benign chronic neutropenia. S Afr Med J $1975 ; 49 ; 692$.

[12] Dale DC, Person RE, Bolyard AA, Aprikyan AG, Bos C, Bonilla MA, et al. Mutations in the gene encoding neutrophil elastase in congenital and cyclic neutropenia. Blood 2000;96;2317-22.

[13] Newburger PE, Pindyck TN, Zhu Z, Bolyard AA, Aprikyan AAG, Dale DC, et al. Cyclic neutropenia and severe congenital neutropenia in patients with a shared ELANE mutation and paternal haplotype: evidence for phenotype determination by modifying genes. Pediatr Blood Cancer 2010;55;314-17.

[14] Lange RD. Cyclic hematopoiesis: human cyclic neutropenia. Exp Hematol 1983;11;435-51.

[15] Donowitz GR, Maki DG, Crnich CJ, Pappas PG, Rolston KVI. Infections in the neutropenic patient-new views of an old problem. Hematology Am Soc Hematol Educ Program 2001;113-39.

[16] Shi X, Sims MD, Hanna MM, Xie M, Gulick PG, Zheng YH, et al. Neutropenia during HIV infection: adverse consequences and remedies. Int Rev Immunol 2014;33;511-36.

[17] Anabire NG, Aryee PA, Helegbe GK. Hematological abnormalities in patients with malaria and typhoid in Tamale Metropolis of Ghana. BMC Res Notes 2018;11;353.

[18] Hammond WP, Harlan JM, Steinberg SE. Severe neutropenia in infectious mononucleosis. West J Med 1979;131;92-7.

[19] Almeida-Porada GD, Ascensăo JL. Cytomegalovirus as a cause of pancytopenia. Leuk Lymphoma 1996;21;217-23.

[20] Sari R, Buyukberber N, Sevinc A, Bayindir Y, Buyukberber S. Brucellosis in the etiology of febrile neutropenia: case report. J Chemother 2002;14;88-91.

[21] Levine AM, Karim R, Mack W, Gravink DJ, Anastos K, Young M, et al. Neutropenia in human immunodeficiency virus infection: data from the women's interagency HIV study. Arch Intern Med 2006;166;405-10.

[22] Massoll AF, Powers SC, Betten DP. Agranulocytosis occurrence following recent acute infectious mononucleosis. Am J Emerg Med 2017;35;803.e5-803.e6.

[23] Reilly JP, Anderson BJ, Hudock KM, Dunn TG, Kazi A, Tommasini A, et al. Neutropenic sepsis is associated with distinct clinical and biological characteristics: a cohort study of severe sepsis. Crit Care 2016;20;222.

[24] Tesfa D, Keisu M, Palmblad J. Idiosyncratic drug-induced agranulocytosis: possible mechanisms and management. Am J Hematol $2009 ; 84 ; 428-34$.

[25] Andrès E, Zimmer J, Mecili M, Weitten T, Alt M, Maloisel F. Clinical presentation and management of drug-induced agranulocytosis. Expert Rev Hematol 2011;4;143-51.

[26] Castillo LEM, Palmer S, Deal A, Chen SL, Zhu A, Moll S. Incidence and time course of neutropenia in patients treated with rituximab-based therapy for non-malignant immune-mediated hematologic diseases. Blood 2019;134;390.

[27] Wolach O, Bairey O, Lahav M. Late-onset neutropenia after rituximab treatment: case series and comprehensive review of the literature. Medicine (Baltimore) 2010;89;308-18.

[28] Juliá A, Olona M, Bueno J, Revilla E, Rosselló J, Petit J, et al. Drug-induced agranulocytosis: prognostic factors in a series of 168 episodes. Br J Haematol 1991;79;366-71.

[29] Crist WM, Parmley RT, Holbrook CT, Castleberry RP, Denys FR, Malluh A. Dysgranulopoietic neutropenia and abnormal monocytes in childhood vitamin $B_{12}$ deficiency. Am J Hematol 1980;9;89-107.

[30] Chin A. Copper deficiency anemia and neutropenia due to ketogenic diet. Pediatrics 2018;141;e20173286.

[31] Socha DS, DeSouza SI, Flagg A, Sekeres M, Rogers HJ. Severe megaloblastic anemia: vitamin deficiency and other causes. Cleve Clin J Med 2020;87;153-64.

[32] Vallurupalli M, Divakaran S, Parnes A, Levy BD, Loscalzo J. The element of surprise. N Engl J Med 2019;381;1365-71.

[33] Hütter G, Ganepola S, Hofmann WK. The hematology of anorexia nervosa. Int J Eat Disord 2009;42;293-300.

[34] Starkebaum G. Chronic neutropenia associated with autoimmune disease. Semin Hematol 2002;39;121-7. 
[35] Capsoni F, Sarzi-Puttini P, Zanella A. Primary and secondary autoimmune neutropenia. Arthritis Res Ther 2005;7;208-14.

[36] Lamy T, Moignet A, Loughran TP. LGL leukemia: from pathogenesis to treatment. Blood 2017;129;1082-94.

[37] Weinzierl EP, Arber DA. The differential diagnosis and bone marrow evaluation of new-onset pancytopenia. Am J Clin Pathol 2013;139;9-29.

[38] Papadaki HA, Eliopoulos AG, Kosteas T, Gemetzi C, Damianaki A, Koutala H, et al. Impaired granulocytopoiesis in patients with chronic idiopathic neutropenia is associated with increased apoptosis of bone marrow myeloid progenitor cells. Blood 2003;101;2591-600.

[39] Papadaki HA, Stamatopoulos K, Damianaki A, Gemetzi C, Anagnostopoulos A, Papadaki T, et al. Activated T-lymphocytes with myelosuppressive properties in patients with chronic idiopathic neutropenia. Br J Haematol 2005;128;863-76.

[40] Flowers CR, Seidenfeld J, Bow EJ, Karten C, Gleason C, Hawley DK, et al. Antimicrobial prophylaxis and outpatient management of fever and neutropenia in adults treated for malignancy: American Society of Clinical Oncology clinical practice guideline. J Clin Oncol 2013;31;794-810.

[41] Andersohn F, Konzen C, Garbe E. Systematic review: agranulocytosis induced by nonchemotherapy drugs. Ann Intern Med 2007;146;657-65.

[42] Semenzato G, Zambello R, Starkebaum G, Oshimi K, Loughran TP. The lymphoproliferative disease of granular lymphocytes: updated criteria for diagnosis. Blood 1997;89;256-60.

[43] Lucas G, Porcelijn L, Fung YL, Green F, Reil A, Hopkins M, et al. External quality assessment of human neutrophil antigen (HNA)specific antibody detection and HNA genotyping from 2000 to 2012. Vox Sang 2013;105;259-69.

[44] Dale DC. How I diagnose and treat neutropenia. Curr Opin Hematol 2016;23;1-4.

[45] Mehta HM, Malandra M, Corey SJ. G-CSF and GM-CSF in neutropenia. J Immunol 2015;195;1341-9. 